\title{
Comparing open reduction and internal fixation versus closed reduction using dual-point distraction and percutaneous fixation for treating calcaneal fractures
}

\author{
Sefa Giray Batıbay, $\mathrm{MD}^{1}{ }^{1}$, Serkan Bayram, $\mathrm{MD}^{2}$ (D) \\ 1Department of Orthopedics and Traumatology, Derince Training and Research Hospital, Kocaeli, Turkey \\ ${ }^{2}$ Department of Orthopedics and Traumatology, Istanbul University Faculty of Medicine, Istanbul, Turkey
}

Restoration of the heel height and length, realignment of the posterior facet of the subtalar joint and restoration of the mechanical axis of the hindfoot are the targets to be achieved in the surgical treatment of calcaneus fractures. ${ }^{[1]}$ The gold standard treatment for displaced intraarticular calcaneus fractures remains controversial. ${ }^{[2,3]}$ The extended lateral approach and open reduction and internal fixation (ORIF) have traditionally been used for the fixation of most displaced intraarticular calcaneal fractures, which are considered gold standard treatments. However, these treatments are associated with a high incidence of complications such as wound complications, peroneal tendonitis and infections. ${ }^{[4,5]}$

Various minimally invasive techniques have been described to prevent these complications. ${ }^{[6,7]}$ Closed reduction and minimally invasive fixation assisted with bidirectional distraction have been successfully and safely used for calcaneus fractures. ${ }^{[8-10]}$ The surgical technique involving a dual-point distractor has been described as an alternative for the management of joint depression-

Received: November 14, 2019

Accepted: January 01, 2020

Published online: March 26, 2020

Correspondence: Serkan Bayram, MD. İstanbul Üniversitesi İstanbul Tıp Fakültesi Ortopedi ve Travmatoloji Anabilim Dalı, 34093 Çapa, Fatih, İstanbul, Türkiye.

E-mail: dr.serkanbayram89@gmail.com

Doi: 10.5606/ehc. 2020.72236

Citation: Batıbay SG, Bayram S. Comparing open reduction and internal fixation versus closed reduction using dual-point distraction and percutaneous fixation for treating calcaneal fractures. Jt Dis Relat Surg 2020;31(2):193-200.

\section{ABSTRACT}

Objectives: This study aims to compare the early clinical, functional and radiographic outcomes of a small cohort of patients with calcaneal fractures treated with closed reduction using a dualpoint distraction system and the traditional lateral approach.

Patients and methods: We prospectively treated 40 patients with calcaneus fractures who presented to our emergency department between January 2017 and February 2018. In total, 35 patients (22 males, 13 females; median age 39.8 years; range, 19 to 57 years) were included in this study since five patients were not followed up. Fractures were classified according to the Sanders classification system using computer tomography images. Clinical outcomes including postoperative two-week visual analog scale (VAS) score, sickness absence period, operating time and complication rate were recorded.

Results: The mean follow-up period was 24 months. Closed reduction using dual-point distraction and percutaneous fixation (group 1) was performed in 17 patients, whereas the extended lateral approach (group 2) was used in 18 patients. There were no significant differences between both groups in age, follow-up outcomes and Sanders classification. Operating time was significantly shorter in group 1 than in group 2 . At postoperative two weeks, VAS scores were significantly lower in group 1 than in group 2 . The complication rate and sickness absence period were significantly lower in group 1 than in group 2 .

Conclusion: Closed reduction using dual-point distraction can be preferred owing to many advantages including considerably decreased risk of wound complications, sickness absence period and length of hospital stay as well as superior postoperative rehabilitation with a low pain score.

Keywords: Calcaneal fracture, distraction and percutaneous fixation, dual point distraction, minimally invasive..

type fractures and comminuted fractures. ${ }^{[9]}$ In this study, we aimed to compare the early clinical, functional and radiographic outcomes of a small cohort of patients with calcaneal fractures treated with closed reduction using a dual-point distraction system and the traditional lateral approach. 


\section{PATIENTS AND METHODS}

We prospectively treated 40 patients with calcaneus fractures who presented to our emergency department between January 2017 and February 2018. In total, 35 patients (22 males, 13 females; median age 39.8 years; range, 19 to 57 years) were included since five patients were not followed up. The study protocol was approved by the Ümraniye Training and Research Hospital Ethics Committee (no.: 15873). A written informed consent was obtained from each patient. The study was conducted in accordance with the principles of the Declaration of Helsinki.

The complication rate was the primary outcome parameter in our study. Sample size was calculated based on previous studies. ${ }^{[4,5,7]}$ The complication rate altered $0-6.5 \%$ in minimal invasive percutaneous treatment group and $12-30 \%$ in lateral extensile approach group. Hence, a minimum sample size of 17 was calculated for each group. With expectation of dropouts, 20 patients per group were included.

A variable block schedule was created on a computer system for randomization. A randomization list was generated by an independent statistician. The list containing the resulting treatment groups was stored in sealed non-transparent envelopes. Patients with diabetes mellitus, osteoporosis (T-score <-2.5) and a history of osteoporosis drug therapy, previous ipsilateral foot surgery or fracture, chronic fracture and open fracture were excluded. Patients aged $>18$ years with a minimum one-year follow-up as well as unilateral and acute calcaneus fractures were considered eligible. All operations were performed by a single surgeon. Fractures were classified according to the Sanders classification system using computer tomography (CT) images. ${ }^{[1]]}$

Primary clinical outcomes including pre- and postoperative visual analog scale (VAS) score, sickness absence period, operating time and complications (wound complications and postoperative peroneal tendinopathy) were recorded. Visual analog scale scores measured in centimeters (range, 0-10.0 cm) were used to track patients' daily pain scores during the pre- and postoperative phases as well as at postoperative two weeks.

Secondary clinical outcomes including timing of surgery, postoperative length of hospital stay as well as American Orthopaedic Foot and Ankle Society (AOFAS) $^{[12]}$ and Foot and Ankle Disability Index (FADI) scores ${ }^{[13]}$ at postoperative six-month and final follow-up visit were used to quantify the functional outcomes and compare the study groups.
Radiographic evaluation included measurement of the Böhler and Gissane angles in the pre- and postoperative periods. The Gissane angle is formed by the downward and upward slopes of the calcaneus superior surface and the Böhler angle between the two lines tangent to the calcaneus on a lateral radiograph. ${ }^{[14,15]}$

Closed reduction using dual-point distraction and percutaneous fixation group (group 1): This procedure was performed using regional anesthesia without using a tourniquet. The patients were placed in the lateral decubitus position with the injured foot placed on a leg holder in an upper and strictly horizontal position (Figure 1a, b). A free approach to the whole foot was essential to mount the distraction device appropriately and position the fluoroscope optimally. Two Kirschner (K)-wires were used for distraction, with the first pin inserted in the anterior process of the talus and second pin inserted in the distal plantar region of the tuber calcaneus (Figure 1c, d). The entry points of the pins were marked using the lateral view. After manual correction of the varus with distraction, distraction was applied using the lateral and axial views until an adequate length reduction was achieved. As indicated by the bending of K-wires, significant traction was needed to successfully reduce the fractures. We used an angle-stable, single-point distraction device on the medial side (Figure 2a). The tension in the foot ligaments (particularly the plantar fascia) can help raise the longitudinal arch through ligamentotaxis as the calcaneal length is restored. For the fixation of the axis, length and height, two 6.5-mm cannulated fully threaded screws were used (Figure 2b). Parallel screws in the central zone can be considered beams supporting the fractured joint fragments above. Local soft-tissue complications significantly reduced with the use of an entry point above the upper border of the Achilles tendon insertion. Reduction of the central joint fragments of the posterior facet was achieved with the lift. Kirschner wires were inserted for the preparation for the insertion of $4.0-\mathrm{mm}$ sustentaculum screws (Figure 3). All patients were evaluated postoperatively with CT (Figure 4).

Extended lateral approach group (group 2) (Figure 5): This approach was used under regional anesthesia using a tourniquet. The patients were placed in the supine position, and an incision was performed starting $2 \mathrm{~cm}$ above the lateral malleolus parallel to the Achilles tendon at the posterior sural nerve continuing distally towards the sole of the foot. Then, the incision was turned anteriorly and continued at the junction between the lateral dorsal normal skin and plantar skin until the calcaneocuboid 

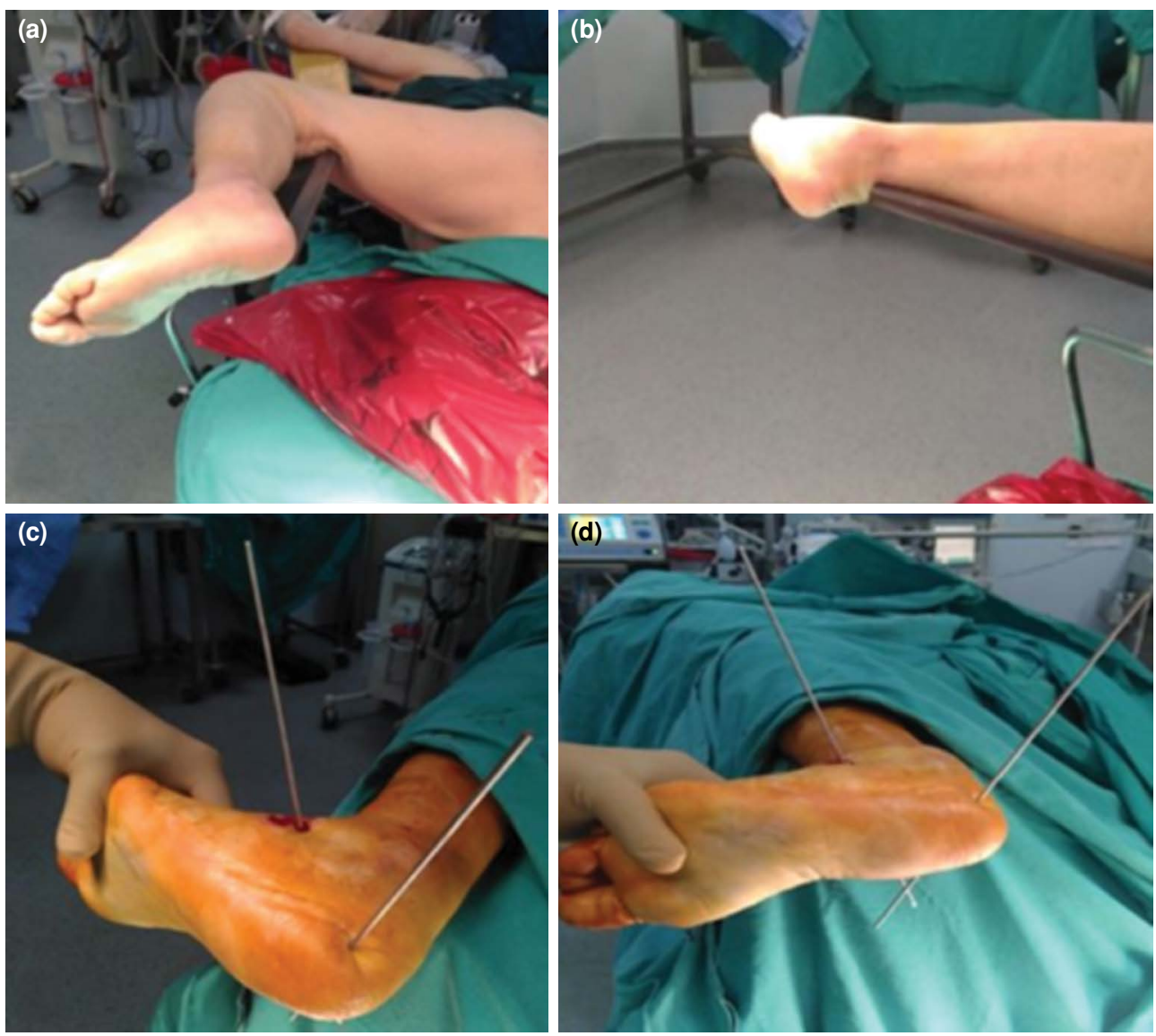

FIGURE 1. (a, b) All patients were placed in lateral decubitus position with injured foot placed on a leg holder in an upper and strictly horizontal position. (c, d) Two Kirschner-wires were used for distraction, with first pin inserted in anterior process of talus and second pin inserted in distal plantar region of tuber calcaneus.

joint; thereafter, a dorsal turn of $1 \mathrm{~cm}$ was performed. The whole layer of the skin flap was separated to fully expose the lateral wall of the calcaneus, subtalar joint and calcaneocuboid joint. A K-wire was drilled to restore the articular surface and fracture reduction. An artificial bone was used to fill the bone defects. When the reduction was satisfactory, as observed by fluoroscopy, a steel plate was inserted for ORIF. The fracture end, calcaneal plate and screw location were confirmed using fluoroscopy (Figure 4).

The affected limbs were elevated to minimize swelling. Passive and active movements of the ankle and subtalar joint were restored without weight bearing at postoperative $24^{\text {th }}$ hour. All patients were treated with analgesic therapy for one week (twice daily, oral administration, $10 \mathrm{mg}$ codeine $+500 \mathrm{mg}$ paracetamol). Partial weight bearing was initiated at postoperative six weeks, and full weight bearing was initiated at postoperative 12 weeks for all groups.
In group 2, a cast was applied for wound healing for postoperative three-five days. A clinical follow-up was performed at postoperative 2, 4, 6 and 12 weeks and at 6 and 12 months. Radiographs were obtained until a radiological union was achieved.

\section{Statistical analysis}

All statistical analyses were conducted using the IBM SPSS version 22.0 software (IBM corp., Armonk, NY, USA). A paired t-test was performed to assess the variation in VAS scores and Gissane and Böhler angles. An independent t-test was performed to compare age, follow-up outcomes, length of hospital stay, operating time, sickness absence period as well as AOFAS and FADI scores at postoperative six-month and final follow-up visits. Fisher's exact test was performed for the comparison of fracture type, peroneal tendinopathy and complication rates between the two groups. P value of $<0.05$ was regarded as statistically significant. 

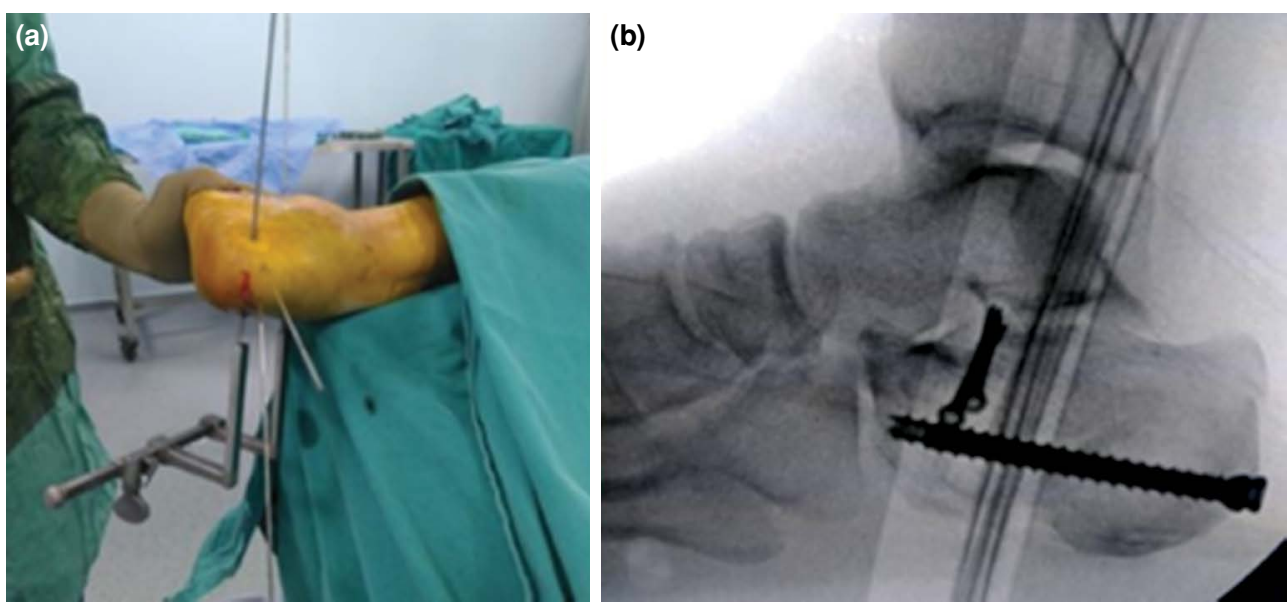

FIGURE 2. (a) Dual-point distraction device on medial side. (b) For fixation of axis, length and height, two $6.5-\mathrm{mm}$ cannulated fully threaded screws, reduction of central joint fragments of posterior facet, and 1-2 4.0 cannulated screws were used.

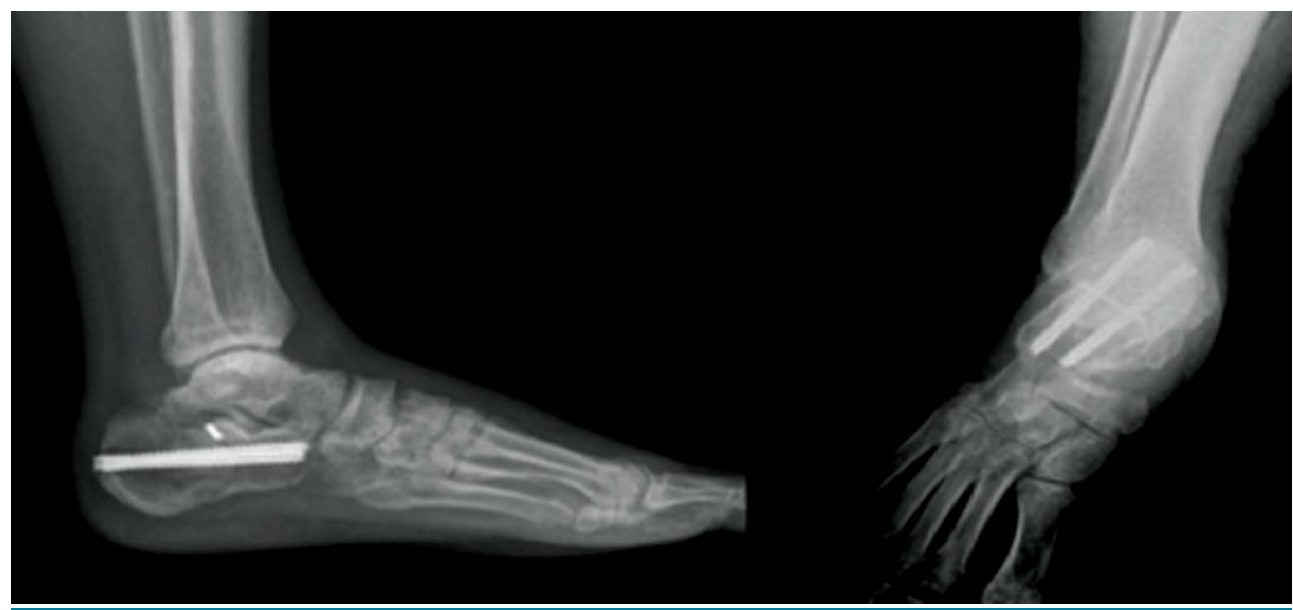

FIGURE 3. Postoperative anteroposterior and lateral views of closed reduction using dual-point distraction and percutaneous fixation group.

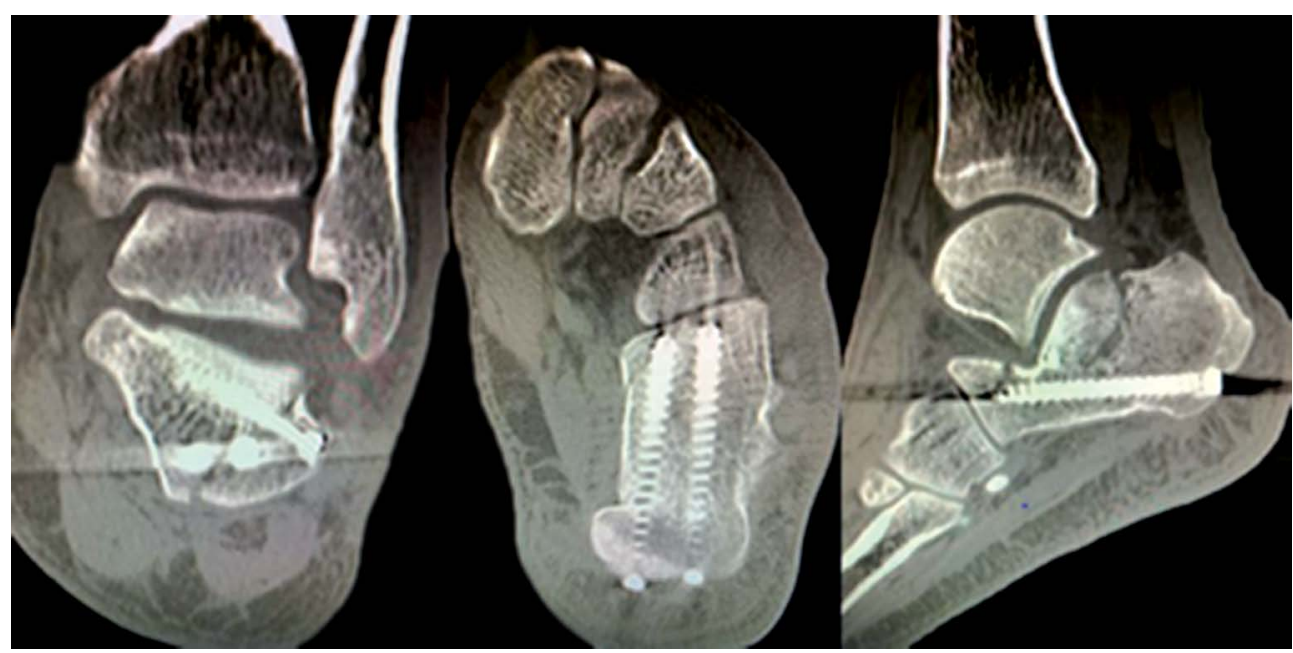

FIGURE 4. Postoperative computer tomography images of closed reduction using dual-point distraction and percutaneous fixation group. 

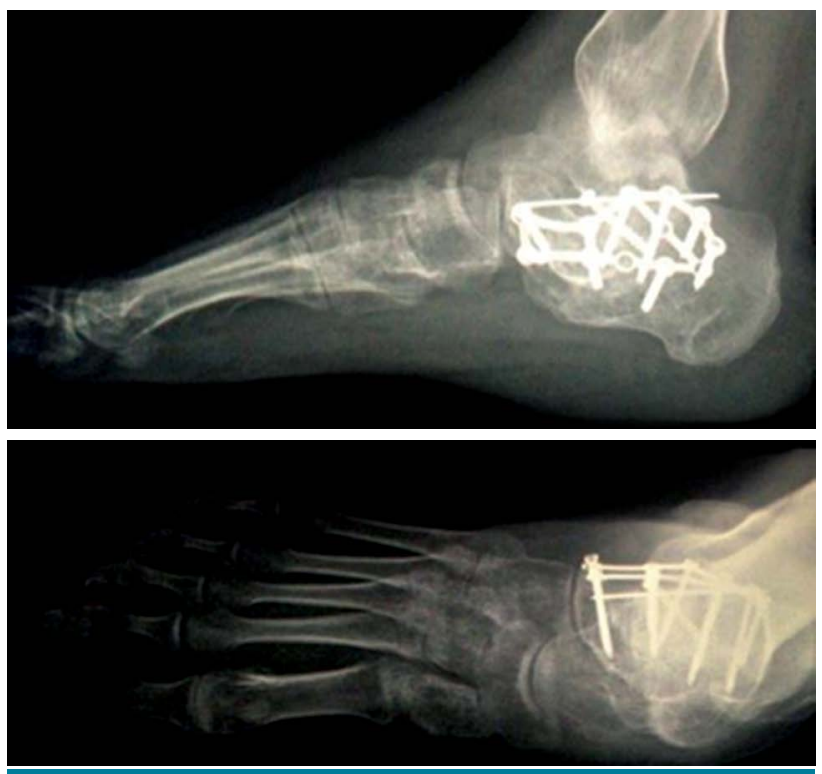

FIGURE 5. Postoperative anteroposterior and lateral images of extended lateral approach group.

\section{RESULTS}

Closed reduction using dual-point distraction and percutaneous fixation was performed in 17 patients, whereas the extended lateral approach was used in 18 patients. The average age in group 1 was 40.2 years and that in group 2 was 39.2 years, with no significant difference between the groups in this regard $(p=0.98)$. The average follow-up period was 23.2 months for group 1 and 25.3 months for group $2(p=0.13)$. According to the Sanders classification system, five patients had type II fracture, six had type III fracture and six had type IV fracture in group 1; further, five patients had type II fracture, seven had type III fracture and six had type IV fracture in group 2. There were no significant differences between the groups in this regard $(\mathrm{p}=0.59)$.

Operating time was significantly shorter in group 1 than that in group $2(43.5 \pm 10.1$ vs. $69.3 \pm 16.2$ minutes; $\mathrm{p}<0.001)$. Group 1 was superior to group 2 in terms of postoperative VAS scores. At postoperative two weeks, VAS scores for group 1 (2.1 \pm 1.1$)$ were significantly lower than those for group 2 (3.7 \pm 1.5 , $\mathrm{p}<0.01)$.

Timing of surgery was $2.64 \pm 1.36$ days (range, 1-6 days) in group 1 and $8.11 \pm 1.45$ days (range, 6-11 days) in group 2. There were significant differences between the two groups $(\mathrm{p}<0.0001)$.

Complication rate was significantly lower in group $1(16.6 \%)$ than in group $2(62.5 \%, \mathrm{p}<0.001)$. There were two patients with peroneal tendinopathy in group 1 and 10 patients in group $2(p=0.01)$. There were no wound complications in group 1 , but three patients in group 2 had wound infection $(p=0.03)$.

The average sickness absence period was 82.1 days (range, 68-100 days) in group 1 and 118.8 days (range, 90-152 days) in group 2. There were significant differences between the two groups in this regard $(\mathrm{p}<0.001)$, and group 1 resumed work earlier than group 2 (Table I).

No significant differences were noted in terms of pre- and postoperative Gissane and Böhler angles between groups 1 and $2(p=0.87$ vs. $p=0.41)$, while remarkable differences were found between pre- and postoperative values in both groups (Table II).

The AOFAS score at the postoperative six-month visit was 90 \pm 2.8 (range, 83-93) and at the final follow-up visit was 95.7 \pm 3.3 (range, 88-100) in group 1 and $78 \pm 6.3$ (range, 57-88) and $86.8 \pm 9.3$ (range, 72-97),

\section{TABLE I}

Comparison of demographic data and primary outcomes between both groups

\begin{tabular}{|c|c|c|c|c|c|c|c|}
\hline & \multicolumn{3}{|c|}{$\begin{array}{l}\text { Closed reduction using dual-point } \\
\text { distraction group }\end{array}$} & \multicolumn{3}{|c|}{$\begin{array}{l}\text { Extended lateral approach } \\
\text { group }\end{array}$} & \multirow[b]{2}{*}{$p$} \\
\hline & $\%$ & Mean $\pm S D$ & Min-Max & $\%$ & Mean \pm SD & Min-Max & \\
\hline Age (year) & & $40.2 \pm 10$ & $19-56$ & & $39.2 \pm 9$ & $19-57$ & 0.98 \\
\hline Follow-up (month) & & $23.2 \pm 3.6$ & $12-30$ & & $25.3 \pm 4.4$ & $12-32$ & 0.13 \\
\hline Operating time (min) & & $43.5 \pm 10.1$ & $30-65$ & & $69.3 \pm 11.2$ & $50-80$ & $<0.001$ \\
\hline Preoperative visual analog scale & & $7.2 \pm 3.2$ & $4-9$ & & $7.8 \pm 3.1$ & $5-9$ & 0.42 \\
\hline Postoperative visual analog scale & & $2.1 \pm 1.1$ & $1-4$ & & $3.7 \pm 1.5$ & $1-5$ & $<0.01$ \\
\hline Sickness absence period (day) & & $82.1 \pm 10.1$ & $68-100$ & & $118.8 \pm 18.9$ & $90-152$ & $<0.001$ \\
\hline Complications & 16.6 & & & 62.5 & & & $<0.001$ \\
\hline
\end{tabular}




\begin{tabular}{|c|c|c|c|c|c|}
\hline Comparison & ographic anc & $\begin{array}{l}\text { LE II } \\
\text { ctional resul }\end{array}$ & between bo & roups & \\
\hline & $\begin{array}{l}\text { Closed re } \\
\text { dual-point } 0\end{array}$ & $\begin{array}{l}\text { tion using } \\
\text { ction group }\end{array}$ & $\begin{array}{l}\text { Exten } \\
\text { appro }\end{array}$ & $\begin{array}{l}\text { lateral } \\
\text { group }\end{array}$ & \\
\hline & Mean $\pm S D$ & Min-Max & Mean $\pm S D$ & Min-Max & $p$ \\
\hline Böhler angle & & & & & \\
\hline Preoperative & $11.2 \pm 5$ & $7-15$ & $13.1 \pm 6.1$ & $6-16$ & 0.41 \\
\hline Postoperative & $26 \pm 6.2$ & $14-34$ & $28.2 \pm 5.2$ & $20-36$ & 0.12 \\
\hline Gissane angle & & & & & \\
\hline Preoperative & $112.2 \pm 11$ & $98-126$ & $114.3 \pm 14$ & $90-121$ & 0.87 \\
\hline Postoperative & $135.8 \pm 9.1$ & $120-145$ & $136.2 \pm 11$ & $118-146$ & 0.32 \\
\hline AOFAS score & & & & & \\
\hline $6^{\text {th }}$ months & $90 \pm 2.8$ & $83-93$ & $78 \pm 6.3$ & $57-88$ & $<0.001$ \\
\hline Final visit & $95.7 \pm 3.3$ & $88-100$ & $86.8 \pm 9.3$ & $72-97$ & 0.004 \\
\hline FADI score & & & & & \\
\hline $6^{\text {th }}$ months & $84 \pm 4.3$ & $76-88$ & $72.7 \pm 7.2$ & $61-85$ & $<0.001$ \\
\hline Final visit & $91.5 \pm 5.8$ & $91-96$ & $82.4 \pm 9.3$ & $73-98$ & 0.002 \\
\hline Length of hospital stay (days) & $3.7 \pm 1.2$ & $2-6$ & $5.7 \pm 2.2$ & $4-8$ & $<0.001$ \\
\hline
\end{tabular}

respectively, in group 2 ( $\mathrm{p}<0.001$ vs. $\mathrm{p}=0.004)$. Foot and Ankle Disability Index score at the postoperative six-month visit was $84 \pm 4.3$ (range, 76-88) and at the final follow-up visit was 91.5 \pm 5.8 (range, 91-96) in group 1 and $72.7 \pm 7.2$ (range, 61-85) and 82.4 \pm 9.3 (range, 73-98), respectively, in group 2 ( $<<0.001$ vs. $p=0.002$ ). Patients who underwent closed reduction using distraction had significantly higher AOFAS and FADI scores at the postoperative six-month and final follow-up visit (Table II).

The mean length of postoperative hospital stay was 3.7 \pm 1.2 days (range, 2-6 days) in group 1 and $5.7 \pm 2.2$ days (range, $4-8$ days) in group 2. There were significant differences between both groups in this regard, with group 1 having significantly earlier discharge $(\mathrm{p}<0.001)$.

\section{DISCUSSION}

The percutaneous fixation approach using distraction forces is the oldest operative treatment for intraarticular calcaneal fractures. A dual-point distractor with or without K-wire fixation has been used in several studies. ${ }^{[16-18]}$ Although many studies have described and investigated the percutaneous fixation approach using a distraction system, no study has compared this technique with the traditional extended lateral approach. In this study, we used dual-point distraction, which was found to be more effective than the extended lateral approach.
Wong-Chung et al. ${ }^{[19]}$ found dislocation of the peroneal tendons in 19 of 79 patients (24\%) with calcaneus fractures. In another study, Jandová et al. ${ }^{[20]}$ found significant differences between injured and healthy feet in an extended lateral approach group. In our study, peroneal tendon complaints were less in group 1, which may be because of the greater impact of the peroneal tendons in the extended lateral approach.

Saß et al ${ }^{[8]}$ used distractor-assisted reduction and grafting for 42 cases of calcaneal fractures and six of subtalar arthrodesis. The mean length of hospital stay was seven days. In our study, the mean length of hospital stay was $3.7 \pm 1.2$ days after distractor-assisted closed reduction. The possible reason for this is that we did not use grafts and patients who underwent arthrodesis were not examined. In our study, we found that group 1 underwent early operation than group 2.

Mortelmans et al. ${ }^{[21]}$ reported an average sickness absence period of 260.5 days after calcaneus fractures. In our study, the average sickness absence period was 82.1 days in group 1 and 118.8 days in group 2. When the return-to-work period was compared, we found that group 1 resumed work earlier.

Many studies have compared the extended lateral approach and minimally invasive techniques to minimize the wound complication rate. ${ }^{[22-25]}$ Most commonly, the sinus tarsi approach was used because 
it provides a direct exposure of the posterior facet. Kline et al. ${ }^{[22]}$ reported an overall wound complication rate of $6 \%$ in patients treated using the minimally invasive sinus tarsi approach. Xia et al. ${ }^{[23]}$ also reported shorter operating times and lower wound complication rates using the minimally invasive sinus tarsi approach than with using the extended L-shaped lateral approach. Closed reduction using dual-point distraction was minimally invasive and showed decreased postoperative pain and sickness absence period as well as a shortened length of hospital stay. In our study, sickness absence period and length of hospital stay were significantly shorter in group 1 than in group 2 ( $p<0.001$ vs. $p<0.001)$. Neither of the injuries occurred in the two groups in that study, and closed reduction using dual-point distraction generally prevents complications in our patients.

This study has certain limitations. First, we included a relatively small number of patients. Second, the average follow-up period was only 24 months; a longer follow-up period is needed to adequately assess the arthritic changes in the subtalar joint, which are among the most common complications. Third, loss to follow-up could potentially be a significant limitation of our study. In this study, the quality of fracture reduction was not assessed according to subtalar arthrosis. Lastly, patient-specific covariates such as smoking habit and medical comorbidities were not evaluated.

In conclusion, to thebest of ourknowledge, this is the first prospective, randomized study which compared the traditional treatment using the L-shaped lateral approach and closed reduction using distraction. Closed reduction using dual-point distraction can be preferred owing to many advantages including a considerably decreased risk of wound complications, sickness absence period and length of hospital stay as well as superior postoperative rehabilitation with a low pain score.

\section{Declaration of conflicting interests}

The authors declared no conflicts of interest with respect to the authorship and/or publication of this article.

\section{Funding}

The authors received no financial support for the research and/or authorship of this article.

\section{REFERENCES}

1. Dhillon MS, Bali K, Prabhakar S. Controversies in calcaneus fracture management: a systematic review of the literature. Musculoskelet Surg 2011;95:171-81.

2. Aslan A, Sargın S, Gülcü A, Konya MN. Clinical, radiological and patient-reported outcomes in intra-articular calcaneal fractures: Comparison of conservative and surgical treatment. Eklem Hastalik Cerrahisi 2019;30:143-8.

3. Court-Brown CM, Schmied M, Schutte BG. Factors affecting infection after calcaneal fracture fixation. Injury 2009;40:1313-5.

4. Dickens JF, Kilcoyne KG, Kluk MW, Gordon WT, Shawen SB, Potter BK. Risk factors for infection and amputation following open, combat-related calcaneal fractures. J Bone Joint Surg [Am] 2013;95:e24.

5. Fan B, Zhou X, Wei Z, Ren $Y$, Lin W, Hao $Y$, et al. Cannulated screw fixation and plate fixation for displaced intra-articular calcaneus fracture: A meta-analysis of randomized controlled trials. Int J Surg 2016;34:64-72.

6. Arastu M, Sheehan B, Buckley R. Minimally invasive reduction and fixation of displaced calcaneal fractures: surgical technique and radiographic analysis. Int Orthop 2014;38:539-45.

7. Sampath Kumar V, Marimuthu K, Subramani S, Sharma V, Bera J, Kotwal P. Prospective randomized trial comparing open reduction and internal fixation with minimally invasive reduction and percutaneous fixation in managing displaced intra-articular calcaneal fractures. Int Orthop 2014;38:2505-12.

8. Saß M, Rotter R, Mittlmeier T. Minimally invasive internal fixation of calcaneal fractures or subtalar joint arthrodesis using the Calcanail ${ }^{\circledR}$. Oper Orthop Traumatol 2019;31:149-64.

9. Mattiassich G, Litzlbauer W, Ponschab M, Ortmaier R, Rodemund C. [Minimally invasive treatment of intraarticular calcaneal fractures with the 2-point distractor]. Oper Orthop Traumatol 2017;29:149-62.

10. Kádas I, Szita J, Zadravecz G, Hangody L, Dóczi J. Stabilization of calcaneus fractures in a closed manner with a distraction screw. Joint Dis Rel Surg 2008;19:45-9.

11. Sanders R, Fortin P, DiPasquale T, Walling A. Operative treatment in 120 displaced intraarticular calcaneal fractures. Results using a prognostic computed tomography scan classification. Clin Orthop Relat Res 1993;290:87-95.

12. Kitaoka HB, Alexander IJ, Adelaar RS, Nunley JA, Myerson MS, Sanders M. Clinical rating systems for the anklehindfoot, midfoot, hallux, and lesser toes. Foot Ankle Int 1994;15:349-53.

13. Martin RL, Burdett RG, Irrgang JJ. Development of the Foot and Ankle Disability Index (FADI). J Orthop Sports Phys Ther 1999;29:A32-A33.

14. Gillette E. An apparatus for treatment of fractures of the os calcis. J Bone Joint Surg [Am] 1930;12:670-71.

15. Böhler L. Diagnosis, pathology, and treatment of fractures of the os calcis. JBJS 1931;13:75-89.

16. Walde TA, Sauer B, Degreif J, Walde HJ. Closed reduction and percutaneous Kirschner wire fixation for the treatment of dislocated calcaneal fractures: surgical technique, complications, clinical and radiological results after 2-10 years. Arch Orthop Trauma Surg 2008;128:585-91.

17. McBride E. Fractures of the os calcis; tripod-pin-traction apparatus. J Bone Joint Surg 1944;26:578-9.

18. Baca E, Koluman A. Modified percutaneous fixation for displaced intra-articular calcaneal fractures. Eklem Hastalik Cerrahisi 2019;30:168-74.

19. Wong-Chung J, Marley WD, Tucker A, O'Longain DS. Incidence and recognition of peroneal tendon dislocation associated with calcaneal fractures. Foot Ankle Surg 2015;21:254-9. 
20. Jandová S, Pazour J. [Limited versus Extended Lateral Approach for Osteosynthesis of Calcaneal Fractures Comparison of Temporal and Dynamic Parameters of the Gait Cycle]. Acta Chir Orthop Traumatol Cech 2018;85:57-61.

21. Mortelmans LJ, Du Bois M, Donceel P, Broos PL. Impairment and return to work after intra-articular fractures of the calcaneus. Acta Chir Belg 2002;102:329-33.

22. Kline AJ, Anderson RB, Davis WH, Jones CP, Cohen BE. Minimally invasive technique versus an extensile lateral approach for intra-articular calcaneal fractures. Foot Ankle Int 2013;34:773-80.

23. Xia S, Lu Y, Wang H, Wu Z, Wang Z. Open reduction and internal fixation with conventional plate via L-shaped lateral approach versus internal fixation with percutaneous plate via a sinus tarsi approach for calcaneal fractures - a randomized controlled trial. Int J Surg 2014;12:475-80.

24. Jin C, Weng D, Yang W, He W, Liang W, Qian Y. Minimally invasive percutaneous osteosynthesis versus ORIF for Sanders type II and III calcaneal fractures: a prospective, randomized intervention trial. J Orthop Surg Res 2017;12:10.

25. Yeo JH, Cho HJ, Lee KB. Comparison of two surgical approaches for displaced intra-articular calcaneal fractures: sinus tarsi versus extensile lateral approach. BMC Musculoskelet Disord 2015;16:63. 